\title{
Anesthesia With Mask free Sleep Inducing Balloon In Pediatric Patients; A Tertiary Care Hospital Experience
}

\author{
AK AZAD ${ }^{\mathrm{a}}, \mathrm{M} \mathrm{HAQUE}^{\mathrm{b}}, \mathrm{A} \mathrm{ISLAM}^{\mathrm{c}}$
}

\begin{abstract}
:
Introduction: Children are habitually frightened and become combative during the induction of anesthesia. It is challenging for pediatric anesthesiologists to minimize psychological upset by reducing scaring environment of operating room and to facilitate a smooth induction of anesthesia. Use of force to handle severely anxious and scared children may lead to postoperative behavioral problems.
\end{abstract}

Purpose: There is an immense need to develop a simple device to ensure mask free and stress-less induction for children. Sleep Inducing Balloon is the mask-free and stress-less anesthesia delivery system designed for children which is not only fulfilling the criteria of ideal breathing system but also replaces anxiety with amusement and fear with fun!

Methods: A study was conducted among 100 children between 6 months to 7 years of age, during the period of Apr 2018 to Dec 2018 to find out the induction time of Sleep Inducing Balloon who were scheduled for elective short surgical procedure under general anaesthesia having ASA grading I and II. While doing so, children

Introduction:

One of the challenge for pediatric anesthesiologists is to minimize psychological upset by reducing scaring environment of operating room and to facilitate a smooth induction of anesthesia. Children are habitually frightened and become combative during the induction of anesthesia. It has been reported that more than $40 \%$ of children aged 6 months to 7 years display some distress behavior during the induction of anesthesia and more than $30 \%$ of children resist anesthesiologists during induction. The use of positive

a. Dr (Lt Col) Abul Kalam Azad, Classified Specialist in Anaesthesiology, Combined Military Hospital, Dhaka

b. Dr (Brig Gen) Mozibul Haque, Adviser Anaesthesiologist, Combined Military Hospital, Dhaka

c. $\operatorname{Dr}$ (Brig Gen) Aminul Islam, Director, Bangladesh College of Physicians \& Surgeons, Mohakhali, Dhaka

Address of correspondence: Dr ( $\mathrm{Lt} \mathrm{Col}$ ) Abul Kalam Azad, Classified Specialist in Anaesthesiology, Combined Military Hospital, Dhaka, Mobile no: +8801715010956 , E-mail: azad100864@gmail.com

Received: 05 May, 2019

Accepted: 06 September, 2020 receive constant gas mixture of $5 \mathrm{~L}$ oxygen mixed with 5\% sevoflurane till fall asleep.

Results: A total 100 patients were included in this study to record induction time, heart rate and oxygen saturation to validate the function of Sleep Inducing Balloon. Mean age of the children was $3.50 \pm 1.04$ years, mean weight was 10.7 $\pm 3.24 \mathrm{Kgs}$ and mean heart rate was $120 \pm 8.3 / \mathrm{min}$. Most of the children had ASA grade-I (96\%) and oxygen saturation was $\mathbf{9 9 \%}$. Induction time was $60-80$ seconds in $26 \%$ patients, and $81-100$ seconds in $45 \%$ of the children. In $24 \%$ children the induction time was 101-120 seconds, $5 \%$ children took more than two minutes for induction. There was no failure and adverse events were easy to manage.

Conclusion: Mask free sleep inducing balloon is a safe and successful way of anesthetic induction in pediatric patients. The procedure ensures a stress-free peaceful event in frightened children.

Key Words: anesthetic anxiety, Sleep Inducing Balloon, Mask free, Stress-less, pediatric anesthesia.

(J Bangladesh Coll Phys Surg 2021; 39: 19-23)

DOI: https://doi.org/10.3329/jbcps.v39i1.50449

reinforcement to handle severely anxious and scared children may lead to postoperative behavioral problems. So, there is an immense need to develop a simple device to ensure the mask free and stress-less induction for children. [1, 2, 3]

When selecting breathing system for children account must be taken of the respiratory physiological, anatomical and mechanical factors involved. Breathing systems for small children should ideally be (1) have minimal functional/apparatus dead space (2) be either valveless or fitted with very low resistance valves (3) have small internal gas volumes and (4) be constructed in such a way as to minimize gas turbulence \& flow resistance. [4, 5]

Children don't like needles. Traditionally children have gone under anesthesia by breathing anesthesia gases through an anesthesia mask. But the mask feels suffocating and the gases smell bad. Most of the children express tremendous anxiety and they try their best to resist this antiquated technique physically and verbally. In response, the operating 
theatre staffs need to hold the child tight till completion of induction.

Sleep Inducing Balloon is the mask-free and stress-less anesthesia delivery system designed for children which is not only fulfilling the criteria of ideal breathing system but also replaces anxiety with amusement and fear with fun!

\section{Methods:}

Following approval of institutional ethical committee, this prospective randomized controlled study was carried out at Combined Military Hospital, Dhaka, among 100 children between 6 months to 7 years of age, during the period of Apr 2018 to Dec 2018. The study was conducted among children scheduled for elective short surgical procedure under general anaesthesia having American Society of Anesthesiologists (ASA) Grading I and II. Children anticipated to have a difficult airway, reactive airway disease, recent history of upper airway infection were excluded. Pre-anesthetic check up was done 24 hours prior to surgery and the procedure was explained to the parents and written consent was obtained. Parents were accompanied with the baby inside induction room till induction. On arrival at operation theatre baseline preinduction parameters like heart rate, $\mathrm{SpO}_{2}$ were recorded. Children were instructed or allowed to take deep breath followed by forceful blowing of air into the balloon sitting on parents lap as a part of fun game. In doing so baby receives constant gas mixture of $5 \mathrm{~L}$ oxygen mixed with $5 \%$ sevoflurane till fall asleep.The nasal orifices of the baby remain open, so there is no scope to build up pressure inside the airway up to a level to cause respiratory impediment. Then the induction time, heart rate and $\mathrm{SpO}_{2}$ were recorded.

\section{Configuration of Sleep Inducing Balloon[4, 5]}

The most commonly used Mapleson circuit for children is Jackson Rees modification of Ayre's T-piece which has been revised to assemble Sleep Inducing Balloon by fixing a mouth piece and a plastic blocker at suitable positions of the $\mathrm{T}$ piece, nothing new apparatus or appliances are used. The three arms of the Ayre's T-piece is being configured into Sleep Inducing Balloon as follows:

\section{Jackson Rees Ayre's T-piece:}

a. Side arm is attached to machine end

b. Patient end is the open end of angle piece

c. The third arm is the tail of distensible bag with an exit hole or an opening

\section{Sleep Inducing Balloon configuration:}

d. Sleep Inducing Balloon is being configured by adding a mouth piece at the open end of the distensible bag for inhalation \& exhalation purposes

e. The patient end of the Ayre's T piece is occluded by a plastic blocker

f. The side arm is machine mounted

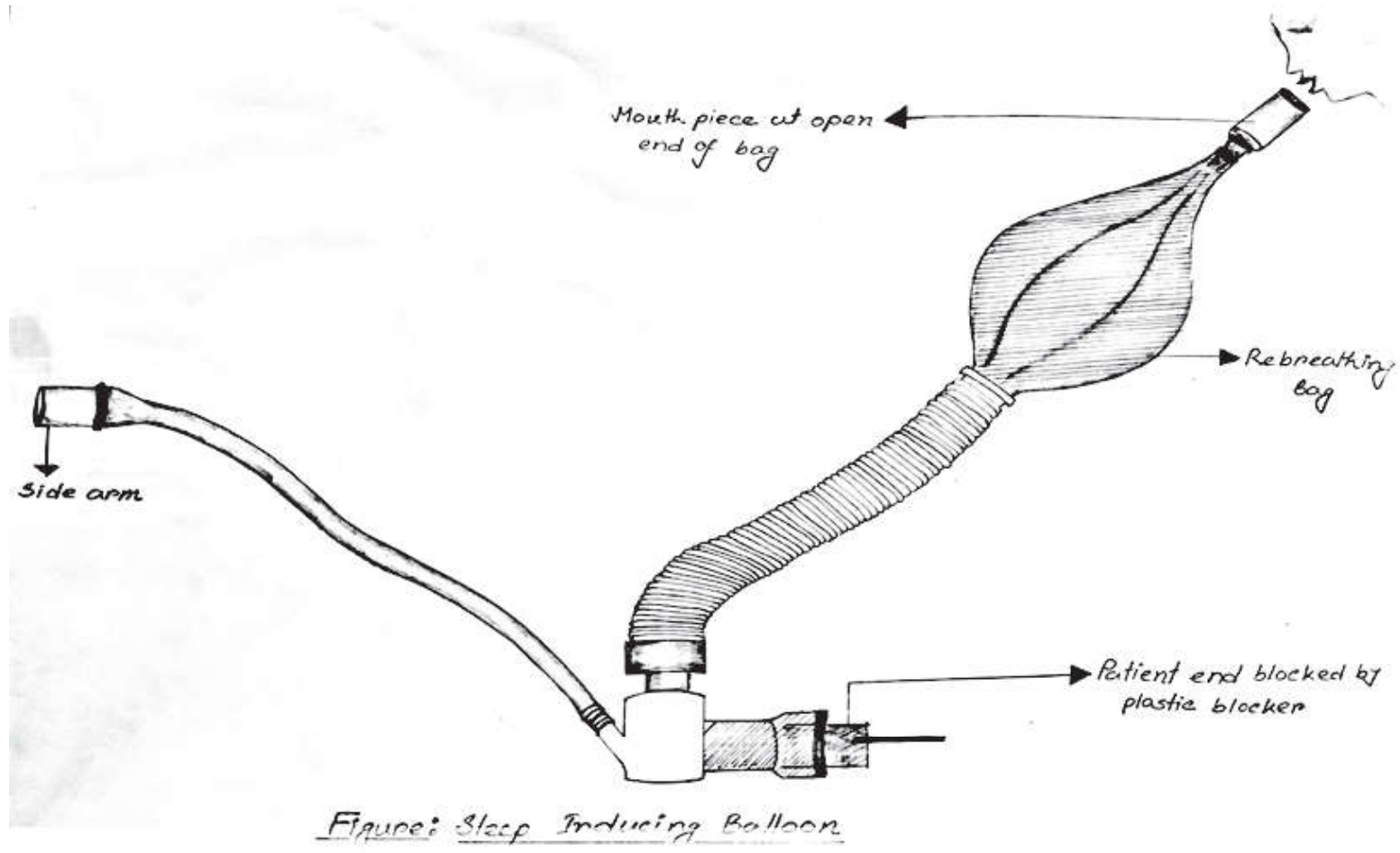




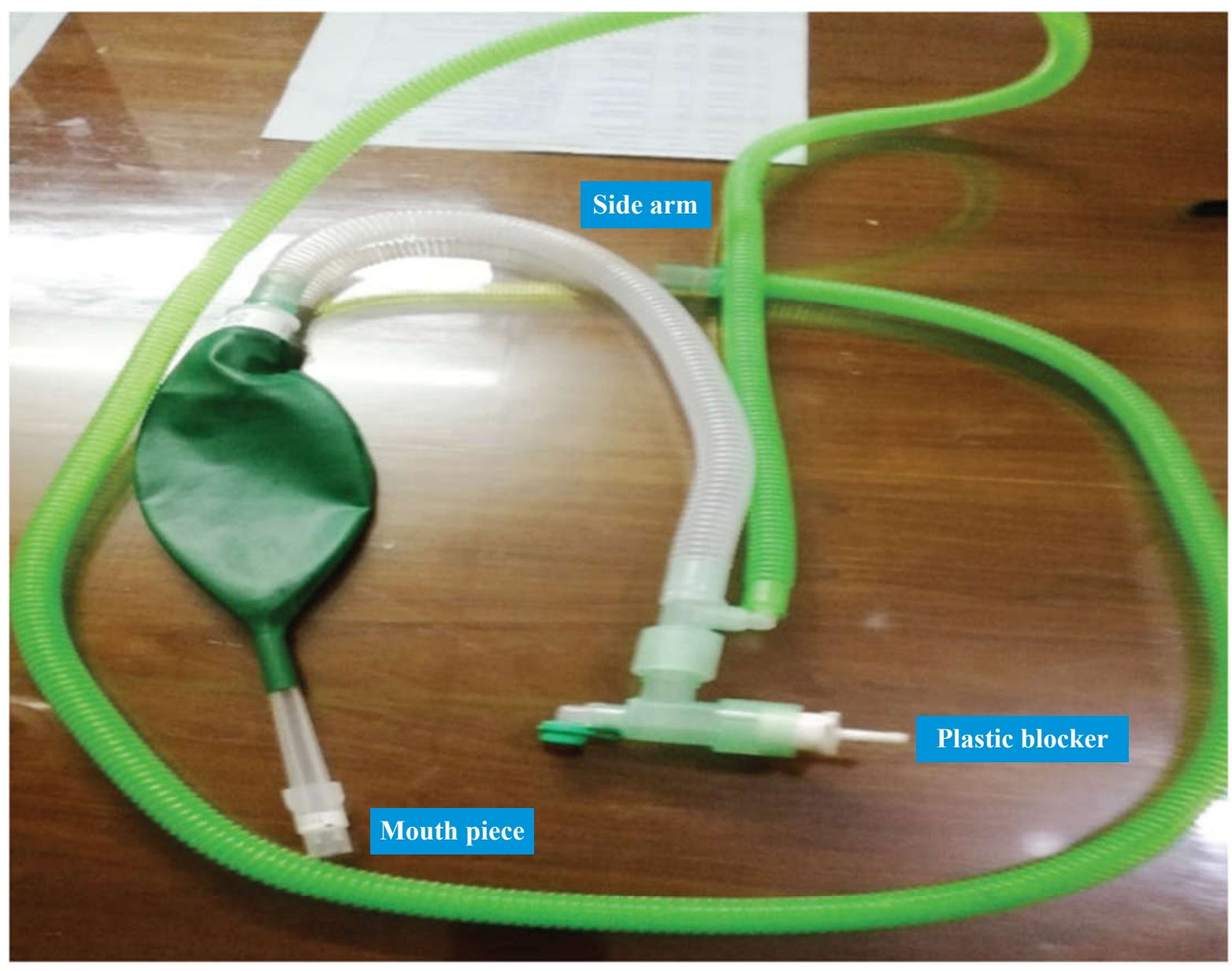

\section{Picture: Improvised Sleep Inducing Balloon}

\section{Techniques of Use Sleep Inducing Balloon : [4]}

The Sleep Inducing Balloon is configured by adding a mouth piece at open end of the distensible bag and the patient end of the T-piece is being occluded by a plastic blocker. Eventually anesthesia proceeded using traditional breathing circuit Jackson Rees modified Ayre's T-piece.

\section{Functional Analysisof Sleep Inducing Balloon:} [4]

Jackson Rees modified Ayre's T-piece will function as dead space free single limb circuit with Fresh Gas Flow by which baby will inhale anesthetic gases mixed with inhalational agent. This single limb Sleep Inducing Balloon does not have expiratory valve rather the baby will exhale spontaneously. The passive expiratory process create positive intra alveolar pressure at end-expiration which drives the air to flow out of lungs.

\section{Results:}

A total 100 patients were included in this study to record induction time, heart rate and oxygen saturation to validate the function of Sleep Inducing Balloon. Demographic characteristics are summarized in Table-I. Mean age of the children was $3.50 \pm 1.04$ years, mean weight was $10.7 \pm 3.24 \mathrm{Kgs}$ and mean heart rate was $120 \pm 8.3 / \mathrm{min}$. Most of the children had ASA grade-I (96\%) and oxygen saturation was $99 \%$. 
Table-I: Demographic characteristics and baseline vitals

\begin{tabular}{|l|c|c|}
\hline Variables & Frequency & Percentage (\%) \\
\hline Age (Years) & $3.50 \pm 1.04$ Years & \\
\hline Sex & & 58.0 \\
M & 58 & 42.0 \\
F & 42 & \\
\hline Weight (Kgs) & $10.7 \pm 3.24 \mathrm{Kgs}$ & \\
\hline ASA Grade (n=100) & 96 & 06.0 \\
I & 04 & 04.0 \\
II & $120 \pm 8.3 / \mathrm{min}$ & \\
\hline HR (per min) & $99 \%$ & \\
\hline SpO $(\%)$ & & \\
\hline
\end{tabular}

Induction time showed in Table-II, which is the duration from application of face mask till the loss of eye lash reflex. It has found that, $45 \%$ children have lost eye lash reflex within 81 to $100 \mathrm{sec}$ time followed by $24 \%$ of them losing eye lash reflex within 61 to $80 \mathrm{sec}$.

Table-II: Induction time of sevoflurane

\begin{tabular}{|l|c|c|}
\hline Induction time (Sec) & Number of children $(\mathbf{n}=\mathbf{1 0 0})$ & Percentage $(\mathbf{\%})$ \\
\hline $61-80$ & 26 & 26.0 \\
\hline $81-100$ & 45 & 45.0 \\
\hline $101-120$ & 24 & 24.0 \\
\hline $121-140$ & 03 & 03.0 \\
\hline$>140$ & 02 & 02.0 \\
\hline
\end{tabular}

Combined data for adverse experiences of induction with sevoflurane showed in Table-III. It has been observed that, secretions $(60.4 \%)$ were the most common adverse effect followed by desaturation $(21.1 \%)$ which was managed by conventional methods and maneuvers.

Table-III: Adverse experiences

\begin{tabular}{|l|c|c|}
\hline Adverse effects & Number of children $(\mathbf{n}=\mathbf{3 8})$ & Percentage $\mathbf{( \% )}$ \\
\hline Cough & 05 & 13.2 \\
\hline Secretions & 23 & 60.4 \\
\hline Laryngospasm & 02 & 5.3 \\
\hline Desaturation & 08 & 21.1 \\
\hline Vomiting & 00 & 0.0 \\
\hline Total & 38 & 100.0 \\
\hline
\end{tabular}




\section{Discussion:}

Inhalational induction of anesthesia is one of the most common methods of induction employed in children because of difficulty in securing intravenous line in awake child and to avoid psychological trauma associated with it. Most often children have gone under anesthesia by breathing anesthesia gases through an anesthesia mask. But the mask feels suffocating and the gases smell pungent. [6]

Children's Mapleson circuit is Jackson Ree's modified Ayre's T-piece which has been improvised into Sleep Inducing Balloon by adding a mouth piece and a plastic blocker at suitable positions of the T-piece, no new equipment's or appliances have been used. The three arms of the Ayre's T-piece is being configured into Sleep Inducing Balloon by adding a mouth piece at the open end of the distensible bag for inhalation \& exhalation purposes, the patient end of the Ayre's T-piece is occluded by a plastic blocker and side arm is attached with machine for fresh gas flow. [4,5]

This simple yet uncomplicated device induces a baby pleasant, stress-less sleep and performed almost similar induction time with other studies such as Muhammad Ilyas et al where mean induction time-96.3 sec was achieved with sevoflurane. [6] Our study is also consistent with P. E. Sigston et al. where induction time $72 \mathrm{sec}$ was demonstrated with sevoflurane. [7]

\section{Limitations of the study:}

1. Frightened children remain reluctant to follow instructions and to blow the balloon

2. Study could not be performed at multiple centers

3. Chance of cross-contamination as parents were accompanying the baby into sterile zone

\section{Conclusion:}

Pleasant and harmonious induction of a baby is a dream of pediatric anesthesiologist. Using the Sleep Inducing Balloon with oxygen mixed with $5 \%$ sevoflurane, the induction time is fast and adverse effects are less. This device provides a safe, pleasant and stress-less sleep and can be a suitable alternative to traditional anesthesia for the pediatric patients.

\section{References:}

1. Marie T. Aouad. The psychological disturbances of the child undergoing surgery-from admission till beyond discharge. M.E.J. Anesth 21 (2), 2011

2. Chorney JM, Kain ZN. Behavioral analysis of children's response to induction of anesthesia. AnesthAnalg, 2009;109:1434-1440, https:/doi.org/ 10.1213/ane. 0b013e3181b412cf, PMid:19713262

3. Kain ZN, Shu MW. Mayes L.C., Caramico LA, Hofstadter MB. Distress during the Induction of Anesthesia and Postoperative Behavioral Outcomes. AnesthAnalg. 1999;8:1042-7, https://doi.org/10.1213/ 00000539-199905000-00013, https://doi.org/ 10.1097/ 00000539-199905000-00013, https://doi.org/ 10.1097/ 00132586-199912000-00033

4. Jerry A. Dorsch, Suson E. Dorsch. Understanding Anesthesia Equipment: Anesthesia Machine \& Breathing Systems. Lippincott Williams \& Wilkins; 4th edition 1998: 218

5. John TB Moylle. Ward's Anesthetic Equipment: Working Principles of Breathing Systems. WB Saunders; 4th edition 1992: 118

6. Ilyas M, Salim S, Rehman RU, Halimi NN. Comparison of mean induction time andemergence from anesthesia between sevoflurane and halothane in children. J Med Sci 2016; 24: (4) 268-272

7. P. E. SigStON, A. M. C. JENKINS, E. A. JACKSON et al. Rapid inhalation induction in children: $8 \%$ sevoflurane compared with5\% halothane. British Journal of Anaesthesia1997; 78: 362-365 